\title{
Phenotyping Techniques for the Selection of Disease Resistance in Pigeonpea Against Phytophthora Cajani
}

\author{
G. Jadesha ${ }^{* 1,2}$, Mamta Sharma ${ }^{1}$ and Narayan Reddy ${ }^{2}$ \\ Legumes Pathology, International Crops Research Institute for the Semi-Arid Tropics, \\ Patancheru-502 324, Andhra Pradesh, India. \\ Received: 25-03-2019 \\ Accepted: 19-08-2019
}

DOI: $10.18805 / \mathrm{LR}-4139$

\begin{abstract}
Different range of temperature and relative humidity were screened against host $\times$ pathogen interaction and temperature of $30^{\circ} \mathrm{C}$ and relative humidity of more than $85 \%$ was induced the maximum infection in the host with shortest incubation period $(18 \mathrm{~h})$. Further different inoculation techniques, inoculum dose and host age were studied for induction of infection in host and development of phytophthora blight disease. Of all soil mixing method of inoculation, inoculum dose of $10 \%$ and plant age of 10-15 days were found most suitable for development of disease. In combination, temperature of $30^{\circ} \mathrm{C}$, relative humidity of more than $90 \%$, soil mixing method of inoculation with $10 \%$ inoculum load can aggravate the disease development in 10-15 days old pigeonpea. Additionally set of 43 improved genotypes screened against P. cajani at field condition. Among all, ICPL 99044, ICP 8863 and ICPL 99055 were showed the resistant reaction.
\end{abstract}

Key words: Disease resistance, Phytophthora, Pigeonpea, Screening technique.

\section{INTRODUCTION}

Pigeonpea [Cajanus cajan (L.) Millsp.] is one of the most important pulse crops of India. It is an integral part of the rainfed farming in many parts of India. Being a hardy crop it is a choice for small and marginal farmers particularly, in semi arid tropics because it can be grown efficiently under low rain fall areas and also low input conditions to provide nutritive food, feed, fodder and fuel wood. Pigeonpea is grown in more than 22 countries of the world including India, among all, India is the largest producer accounting for 66 percent of total production and the other major countries are Myanmar (17.09 percent), Malawi (6.15 percent), Kenya (4.36 percent) and United Republic of Tanzania (5.29 percent). Worldwide 5.41 million ha with an annual production of $4.49 \mathrm{~m}$ tonnes and India alone contributes $72.5 \%$ of world cultivated area with $62.5 \%$ of world production (FAO, 2016). Phytophthora blight is a devastating disease of pigeonpea. Though the disease is sporadic in nature, intermittently it presuppose into epidemic proportions especially in places of heavy and frequent rainfall. Pal et al. (1970) estimated yield losses up to 98 per cent as the affected plants are young one and dries up rapidly. Further Reddy and Sheila, (1994) reported 100 per cent yield loss in shortduration pigeonpea varieties in South India. The recurrence of phytophthora blight as a major menace to pigeonpea production and productivity in the Deccan Plateau of India irrespective of the cultivars, cropping system and soil types (Pande et al. 2011).
A susceptible host, a virulent pathogen and a conducive environment must be present at the same time for a plant disease to occur. If any one of the three is missing for a particular time period, plant disease does not occur. Among environmental factors, temperature and relative humidity are more critical importance in establishing the infectivity of various Phytophthora spp. to different hosts (Timmer et al. 2000). Phytophthora blight disease incidence was higher when maximum temperature $\left(28-30^{\circ} \mathrm{C}\right)$ and relative humidity of $75-96 \%$ when compare to other range of temperature and $\mathrm{RH}$ regimes (Pande and Sharma, 2010). Kannaiyan et al. (1981) reported a pot culture drench inoculation technique and 5 to 10 day old seedlings were best in inducing the phytophthora blight of pigeonpea with mycelial suspension of $P$. drechsleri f. sp. cajani. Nene et al. (1981) reported that, planting of test material with inter planting a susceptible cultivar (ICP 2376 and/or ICP 7119) to serve as an indicator line and the collar region of one month old plants was inoculated with mycelial mats of the fungus after mixing with carborundum will yield phytophthora blight disease for disease resistance. Determining the susceptible stage of the host plant to pathogen will helps to obtain valid results of host plant resistance and ultimately management of disease. Williams et al. (1975) reported that from seedling to the mature fruit stage of host plants are susceptible to Phytophthora cajani. Mishra and Shukla, (1986a) reported the susceptibility of the plants was directly proportional to their age, though the pathogen was able to infect the plants

*Corresponding author's e-mail: jadesha.uasb@gmail.com

AICRP (Maize), ZARS, V C Farm, Mandya, University of Agricultural Sciences, Bengaluru-560 065, Karnataka, India.

${ }^{1}$ Legumes Pathology, International Crops Research Institute for the Semi-Arid Tropics, Patancheru-502 324, Andhra Pradesh, India.

${ }^{2}$ Department of Plant Pathology, Professor Jayashankar Telangana State Agricultural University, Hyderabad-500 030, Telangana, India. 
at all growth stages, but its incidence varied according to age of the plant. The disease incidence was highest at the seedling age of 15 days and declined gradually with increase in the age of the plants.

Information on temperature, relative humidity on pathogen growth and infection in plants, inoculation technique, inoculum dose and plant age and its susceptibility to pathogen is necessary to develop the phenotyping protocol to identify stable resistance sources. Therefore, the objective of the study was to develop a reliable, rapid and economic screening technique to identify pigeonpea cultivars resistant to Phytophthora blight disease.

\section{MATERIALS AND METHODS}

Fungal culture: Pigeonpea plants depicting the typical symptoms of Phytophthora blight were collected from the pigeonpea fields of ICRISAT, Patancheru, Hyderabad. The isolation of pathogen was done according to tissue segment method (Rangaswamy, 1958) using V8 juice agar media (Himedia, Mumbai, India) amended with PARP antibiotics (pimarcin $400 \mu \mathrm{L}$; ampicillin $250 \mathrm{mg}$; rifampicin $1000 \mu \mathrm{L}$; and pentachloronitrobenzine $5 \mathrm{mlL}-1$ media). Pure culture of the fungus was obtained by mono zoospore (Thakur et al. 1998). Pathogen was confirmed by cultural and morphological characteristics as described by (Erwin and Ribeiro, 1996). The fungus was subcultured and maintained on tomato extract agar. Virulence of the pathogen was maintained by transferring the pathogen through susceptible host after every 60 days.

Temperature $\times$ host $\times$ pathogen interaction: Surface sterilized seeds were grown in the plastic pots filled with a mixture of sterilized alfisol comprising of $60 \%$ sand, $33 \%$ clay and $7 \%$ silt (Kannaiyan et al. 1981) kept in a greenhouse maintained at $28-30^{\circ} \mathrm{C}$ for 10 days. Ten day old seedlings were inoculated by soil mixing method of inoculation. Based on our study, growth of $P$. cajani on different temperature regimes showed that temperature of less than $10^{\circ} \mathrm{C}$ and beyond $34^{\circ} \mathrm{C}$ has completely arrested the growth of $P$. cajani in vitro (Data not shown here) hence we selected temperature range of $15,20,25$ and $30^{\circ} \mathrm{C}$ further to study the host $\times$ pathogen $x$ temperature interaction. The inoculated pots were incubated at different temperature regimes maintained in different incubators. Six replications were maintained for each treatment and experiment was repeated twice for confirming the results. Disease was assessed according to per cent disease incidence at the beginning of the incubation period and up to 7 days after inoculation. Per cent disease incidence $(\mathrm{PDI})=($ Total number of infected plants $/$ Total number of plants) $\times 100$.

Relative humidity $\times$ host $\times$ pathogen interaction: Interaction of host and pathogen under different regimes of RH viz., 50, 55, 65, 85, 95 and 100 per cent was studied using the susceptible variety ICP 7119 . The plant growth conditions, multiplication of inoculum, method of inoculation, replications and observation of disease were same as explained in earlier section.

Inoculation techniques and plant infections: An experiment was conducted to identify the best inoculation technique for establishment and development of disease. The inoculation methods includes, T1- soil drenching with mycelial suspension: Seven day old culture disc of $6 \mathrm{~mm}$ diameter of actively expanding mycelium of $P$. cajani isolates were transferred to $100 \mathrm{ml}$ of autoclaved V8 broth in $250 \mathrm{ml}$ flasks and incubated for 2 weeks at $30^{\circ} \mathrm{C}$. The mycelial mats were then removed and macerated with $100 \mathrm{ml}$ of sterile distilled water and inoculated to the plants @ $100 \mathrm{ml} /$ pot. The incubated pots were kept in green house for 7 days at $28 \pm 2^{\circ} \mathrm{C}$. The pots were watered 3 times a day to maintain the adequate moisture for disease development (Kanniyan et al. 1981); T2 - spray inoculation of mycelial suspension: Ten day old seedlings were sprayed with mycelia suspension of $100 \mathrm{ml} /$ pot using automizer. The mycelial suspension was prepared as explained earlier and incubated in greenhouse for 7 days at $28 \pm 2^{\circ} \mathrm{C}$. An uninoculated control was also maintained by spraying with sterile distilled water (Nene et al. 1981). ; T3 - soil mixing with mycelia inoculums: Mass multiplication was done by transferring $6 \mathrm{~mm}$ discs of the fungus growth to 100 gram of sterilized pigeonpea sand flour medium in $250 \mathrm{ml}$ flasks and incubated at $30^{\circ} \mathrm{C}$ with 12 hours of alternate light (2000 Lx) and dark condition for 2 weeks. The medium was sterilized at $121.5^{\circ} \mathrm{C}$ for 20 minutes. Hundred grams of inoculum multiplied on pigeonpea sand flour medium was directly mixed into the soil without disturbing the roots of the seedling on 10 day old seedlings in the pot. Pots were watered 3-4 times at 3-4 $\mathrm{h}$ intervals daily to create adequate soil moisture. T4 - stem inoculation with mycelium: Multiplication of inoculum was done in pigeonpea sand flour medium as explained earlier. Carborandum powder was rubbed on the collar region (base) of 15 day old plants of ICP 7119 and inoculated with $2 \mathrm{~g}$ of inoculum and incubated in greenhouse. Control plants were maintained by mock inoculation.

Inoculum dose and plant infections: Soil mixing with mycelial inoculums was selected further to quantify the optimum inoculum dose to establish the disease. Each pot containing $1 \mathrm{~kg}$ of pot mixture was inoculated using inoculum multiplied on pigeonpea sand flour medium by soil mixing method at the rate of 1.0, 2.5, 5.0, 7.5, 10 and 12.5 per cent of soil weight. Pots were maintained in greenhouse and the disease incidence was estimated in each treatment at different days of inoculation and per cent disease incidence was calculated.

Host age and disease development: The plant age and its susceptibility to disease were determined by inoculating the highly susceptible variety ICP 7119 as described by Sarkar et al. (1992). Sowing of ICP 7119 was taken at different days to obtain plants of all stages viz. 10, 20, 25, 35, 45, 60, $75,90,105$ and 120 at one time and inoculation through soil 
Vol. Issue, ()

mixing with mycelia inocumum method was done at a time and data on disease incidence was calculated at different days after inoculation. Multiplication of inoculum, inoculation method, growth conditions and replications are same as explained earlier section.

Field screening: Forty three improved pigeonpea genotypes Pigeonpea Wilt and Sterility Mosaic Disease Nursery (PWSMDN) lines were screened in research farm (RL-17) of ICRISAT, Patancheru. Soil mixing method of inoculation, inoculum of $10 \mathrm{gram} / \mathrm{plant}$ and 15 days old plants were selected for artificial inoculation. Furrow irrigation was done up to 20 days after post inoculation with an interval of 4 days and care has taken to maintain sufficient soil moisture and facilitate pathogen infection to the host plants. Typical blight symptoms appeared in about 10 days after inoculation. The percentage of blighted seedlings was calculated based on number of infected plants to total number of plants (Chauhan et al. 2002). Based on disease incidence the lines were categorized as per the scale described by Reddy and Jain (1989) where PDI of 0-10 per cent as resistant; 10.1-20 per cent as moderately resistant; $20.1-50$ per cent as moderately susceptible; 50.1-80 per cent as susceptible and 80.1-100 per cent as highly susceptible.

\section{RESULTS AND DISCUSSION}

Temperature is a major environmental factor that regulates plant growth and development as well as its interaction with other organisms (Long and Woodward, 1988). It is also an important factor known to be of critical in governing infectivity of various Phytophthora spp. in different hosts (Gerlach et al. 1976; Timmer et al. 2000). The study host $\times$ pathogen $\times$ temperature implies that, temperature of $30^{\circ} \mathrm{C}$ has greater impact on early infection of host by $P$. cajani with a incubation period (Time between inoculation and expression of first symptoms) of 18 hours (Fig 1A) and 100 per cent disease incidence at seven days of inoculation. Incubation period and temperature levels were inversely proportional to each other. Similar studies reported by Timmer and Zitko, (2000), optimum temperature of 27 to $30^{\circ} \mathrm{C}$ for infection and development of Phytophthora brown rot of citrus. High temperature often inhibits disease resistance or plant immunity (Dropkin, 1969). Zhu et al. (2010) reported that an elevated growth temperature often inhibits plant defence responses and renders plants more susceptible to pathogens. However, the mechanism underlying this modulation is unknown.

Interaction of host $\times$ pathogen under different relative humidity entails that, $\mathrm{RH}$ of more than 85 per cent showed most favourable for pathogen to cause infection in the host with shortest incubation period and highest percent disease incidence (Fig 1B). Incidence of Phytophthora increased at high relative humidity because high humidity favoured the increase in the number of sporangia and aid in
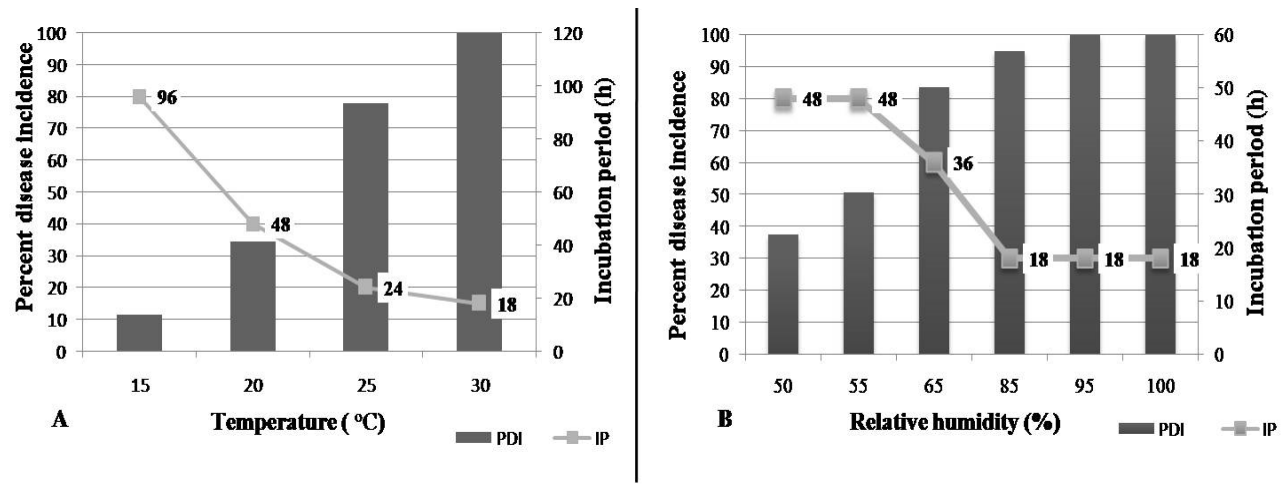

Fig 1: Temperature, relative humidity and infection of pigeonpea by Phytophthora cajani.

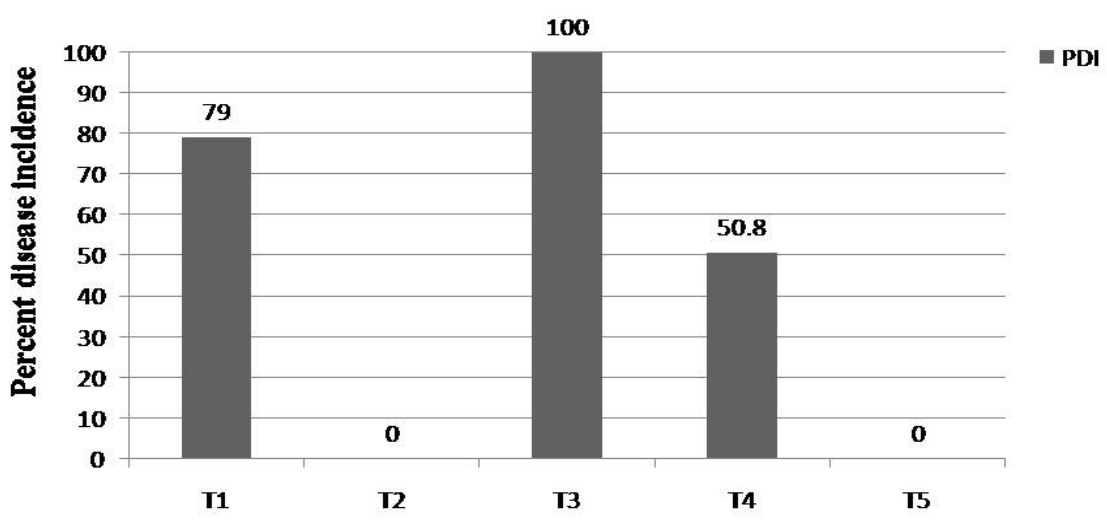

T1- Soil drenching with mycelial suspension: T2- Spray inoculation of mycelial suspension: T3- Soil mixing with mycelial inoculums: T4- Stem inoculation with mycelia inoculums: T5- Unonoculated control.

Fig 2: Screening of inoculation techniques for development of phytophthora blight disease of pigeonpea. 
zoospore liberation, viability and infection of host. The results were in accordance with Pal et al. (1970) who opined increased phytophthora stem rot of pigeonpea was due to increased relative humidity. Lacey (1967) and Rotem et al. (1971) reported late blight of potato developed on potato foliage under conditions when ambient relative humidity is above 90 per cent. Similarly Granke and Hausbeck (2010b) reported increased relative humidity increased the incidence of Phytophthora rot of cucumber fruit.

Soil mixing of mycelial inoculum was found to be the best among all inoculation methods with highest per cent disease incidence and lowest incubation period (Fig 2). Since induction of sparse amount of sporangia was noticed in vitro in the pigeonpea sand flour medium after ten days of incubation with $P$. cajani, hence this could be reason for early disease development when compare to other methods of inoculations. Upon inoculation of mycelial inoculum to soil, induction of sporangia and zoospores takes place in free water and then zoospores will disperse with aid of free water and infect the plants, However under dry conditions sporangia will germinate by germ tube and infect the plants. Results are in accordance with the findings of Kannaiyan et al. (1981).

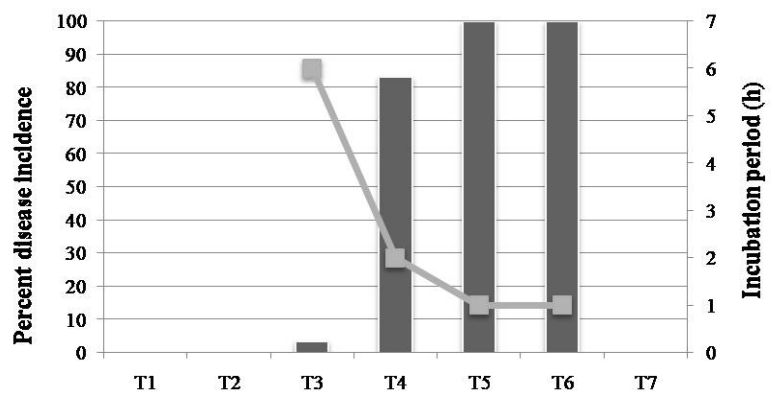

T1-1.0\% of inoculum to soil weight; T2-2.5\%; T3-5.0\%; PDI T4-7.5\%; T5- $10 \%$; T6- $12.5 \%$ and T7- Uninoculated control _-IP

Fig 3: Inoculum concentration and infection of pigeonpea by P. cajani.
The dosage of inoculum need to be selected to characterize better relationship between host and pathogen (McIntyre and Taylor 1976; Milholland et al. 1989). Quantity of inoculum is bound to influence the disease incidence and infection occurs only when minimum inoculum potential of the pathogen is present in the soil. Hence, soil mixing of mycelial inoculum was further selected to quantify the optimum inoculum quantity to establish the disease. Among all inoculums dose, 10.0 per cent and 12.5 per cent of inoculum was found to induce maximum disease incidence with 100 per cent (Fig 3). The amount of initial inoculum determines the amount of disease. The disease increased with the increase in an amount of inoculum quantity and at certain stage addition of extra inoculum did not increase the amount of disease. This could be due to saturation of all the infection courts Van der Plank (1975). In this study both inoculum of 10.0 and 12.5 per cent has shown the same disease incidence. Further it is concluded that, use of 10.0 per cent of inoculum is optimum for inducing the disease.

The relationship of the age of a plant and its susceptibility to a pathogen helps in screening of genotypes against the pathogen. The study was conducted from seedling stage to flowering stage using the soil mixing method of inoculation on susceptible cultivar ICP 7119. Ontogenetically determined resistance is a type of quantitatively inherited resistance that develops during plant maturation (Boyle and Aust, 1997). Study reveals that all the age of plants were susceptible to the disease (Fig 4). it is indicated lack of ontogenic resistance expression in host against $P$. cajani. Similar findings were reported by Masood et al. (2005) and Pande and Sharma (2010) observed pigeonpea susceptible to phytophthora blight irrespective of growth stage both in the field and greenhouse conditions.

Report of availability of resistance to Phytophthora blight disease was identified by various researchers viz. Kannaiyan et al. (1980); Mishra and Shukla (1986b) and

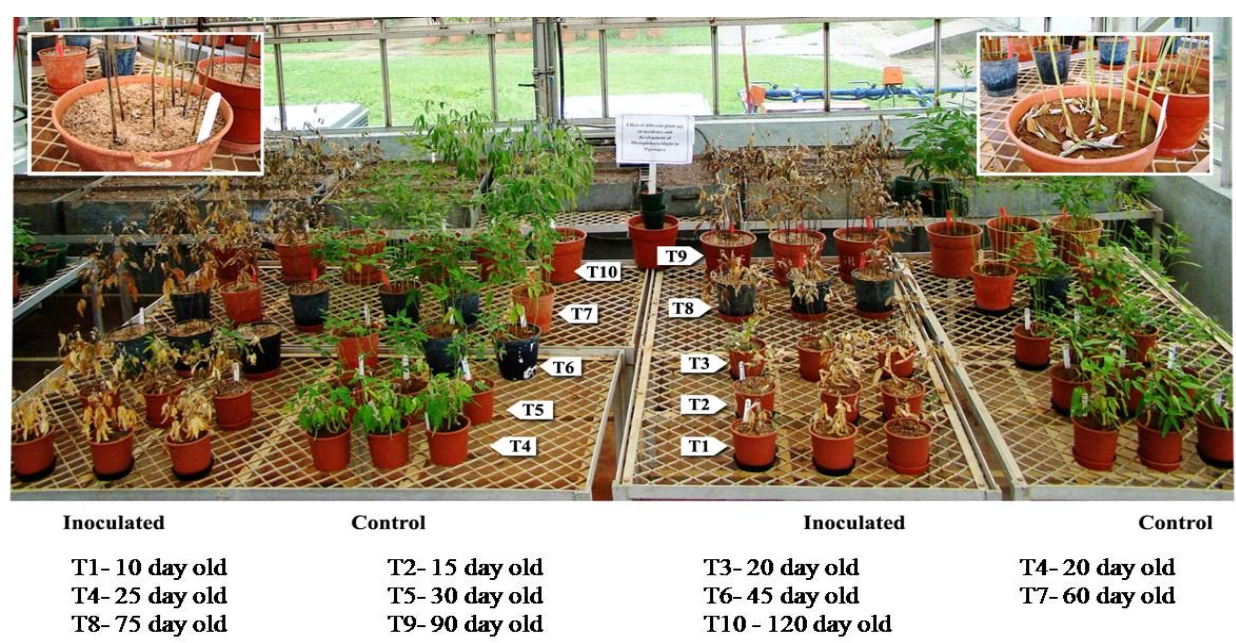

Fig 4: Plant age and development of phytophthora in pigeonpea. 
Vol. Issue, ()

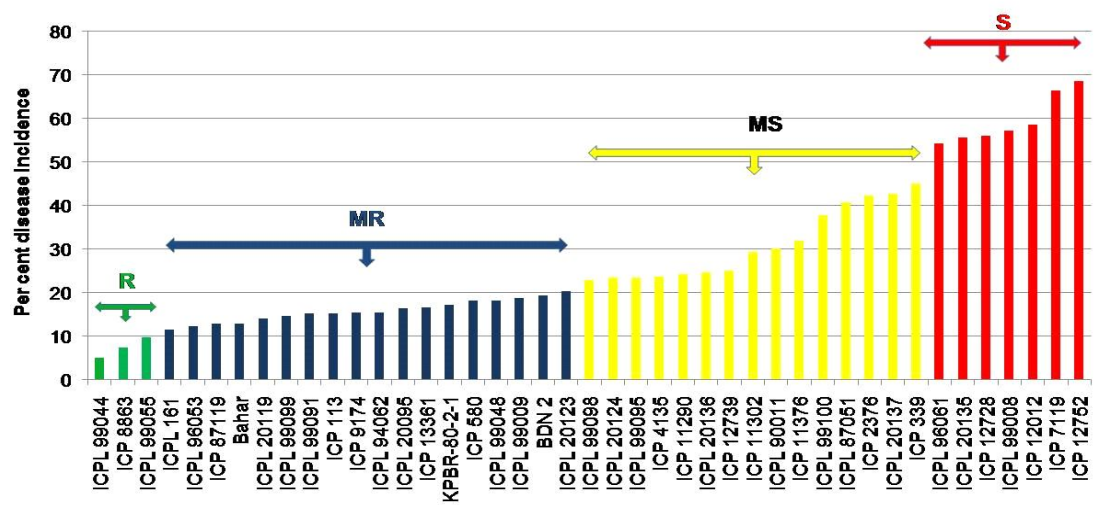

Fig 5: Reaction of improved breeding nursery to Phytophthora cajani at research farm, ICRISAT,Patancheru.

Table 1: Segregation of PWSMD nursery based on disease reaction against $P$. cajani.

\begin{tabular}{|c|c|c|c|}
\hline Disease reaction & Scale & Improved breeding lines & Number \\
\hline Resistant & $0-10$ & ICPL 99044, ICP 8863 and ICPL 99055 & 03 \\
\hline Moderately resistant & $10.1-20$ & $\begin{array}{l}\text { ICPL 161, ICPL 96053, ICP 87119, Bahar, ICPL 20119, ICPL } 99099 \text {, } \\
\text { ICPL 99091, ICP 113, ICP 9174, ICPL 94062, ICPL 20095, ICP 13361, }\end{array}$ & 18 \\
\hline Moderately susceptible & $20.1-50$ & $\begin{array}{l}\text { KPBR-80-2-1, ICP 580, ICPL 99048, ICPL 99009, BDN } 2 \text { and ICPL } 20123 \\
\text { ICPL 99098, ICPL 20124, ICPL 99095, ICP 4135, ICP 11290, ICPL 20136, } \\
\text { ICP 12739, ICP 11302, ICPL 90011, ICP 11376, ICPL 99100, ICPL 87051, } \\
\text { ICP 2376, ICPL } 20137 \text { and ICP } 339\end{array}$ & 15 \\
\hline Susceptible & $50.1-80$ & $\begin{array}{l}\text { ICPL 96061, ICPL 20135, ICP 12728, ICPL 99008, ICP 12012, ICP } 7119 \\
\text { and ICP } 12752\end{array}$ & 07 \\
\hline Highly susceptible & $80.1-100$ & Nil & 00 \\
\hline
\end{tabular}

Reddy et al. (1990). Nevertheless, most of them were later found susceptible to $P$. cajani (Sharma et al. 2006). This could be due to evolution of new pathotypes and coexistence of more than one pathotype at one location. In this connection, we have screened the 43 improved Pigeonpea Wilt and Sterility Mosaic Disease resistant Nursery (PWSMDN) lines which already showed resistance to pigeonpea wilt and sterility mosaic disease.

Of all the PWSMDN, three lines viz., ICPL 99044, ICP 8863 and ICPL 99055 showed least disease incidence less than 10.0 per cent (Fig 5) and found to be resistant to $P$. cajani. Further, 18 lines have showed the incidence between 10.1 to 20.0 per cent against $P$. cajani and categorised as moderate resistant (Table 1) and seven lines showed disease incidence of more than 50 per cent and showed susceptible to $P$. cajani.

\section{REFERENCES}

Boyle, C. and Aust, H.J. (1997). Ontogenetically determined resistance (adult plant resistance). In: Resistance of Crop Plants Against Fungi. [Hartleb Heitefuss R, Hoppe, HH (eds)]. Fischer Verlag, Jena. 254-271.

Chauhan, V.B., Singh, V.B. and Singh, A.K. (2002). Evaluation of pigeonpea genotype for resistance to Phytophthora blight. International Chickpea and Pigeonpea Newsletter. 9: 42.

Dropkin, V. (1969). The necrotic reaction of tomatoes and other hosts resistant to Meloidogyne: reversal by temperature. Phytopathology. 59: $1632-1637$.

Erwin, D. C. and Ribeiro, O. K. (1996). Phytophthora diseases worldwide. American Phytopathological Society, St. Paul, MN. FAO. FAO Year book (Production). Food and Agriculture Organization of the United Nations. 2016.

Gerlach, W. W. P., Hoitink, H. A. J. and Schmitthenner, A. F. (1976). Phytophthora citrophthora on Pieris japonica: Infection, sporulation and dissemination. Phytopathology. 66: 302-308. 
Granke, L.L., Hausbeck, M.K. (2010b). Effects of temperature, humidity and wounding on development of Phytophthora rot of cucumber fruit. Plant Disease. 94 (12):1417-1424.

Kannaiyan, J and Rebeiro, O K and Erwin, D C and Nene, Y L. (1980). Phytophthora blight of pigeonpea in India. Mycologia. 72 (1): $169-181$.

Kannaiyan, J., Nene, Y.L., Raju, T.N. and Sheila, V.K. (1981). Screening for resistance to phytophthora blight of pigeonpea. Plant Disease. 61-62.

Lacey, J. (1967). The role of water in the spread of Phytophthora infestans in the potato crop. Annual Applied Biology. 59: $245-255$.

Long, S.P., Woodward, F.I. (1988). Plants and Temperature. Society for Experimental Biology Cambridge, England: 133.

Masood, A, Singh, B.B., Kumar, S. and Vishwa Dhar. (2005). Advances in pigeonpea research. Indian Society of Pulses Research and Development, IIPR, Kanpur, India. 229-261.

McIntyre, J.L. and Taylor, G.S. (1976). Screening tobacco seedlings for resistance to Phytophthora parasitica var. nicotianae. Phytopathology. 66: 70-73.

Milholland, R.D., Cline, W.O. and Daykin, M.E. (1989). Criteria for identifying pathogenic races of Phytophthora fragariae on selected strawberry genotypes. Phytopathology. 79: 535-538.

Mishra, A.N. and Shukla, P. (1986a). Relation between the age of pigeonpea plant and its susceptibility to Phytophthora blight. Indian Journal of Mycology and Plant Pathology. 16: 292.

Mishra, A.N. and Shukla, P. (1986b). Screening of pigeonpea germplasms against Phytophthora blight. Farm Science Journal. 11(1-2): 84-85.

Nene, Y.L, Kannaiyan, J., Reddy, M.V., (1981). PigeonPea Disease Resistance Screening Techniques. Information Bulletin. (9). ICRISAT, Patancheru andhra Pradesh, India. 5-14.

Pal, M., Grewal, J.S. and Sarbhoy, A.K. (1970). A new stem rot of arhar caused by Phytophthora. Indian Phytopathology. 23: $583-587$.

Pande, S. Sharma, M, Mangla, U. N. Ghosh, R, Sundaresan, G. (2011). Phytophthora blight of pigeonpea [Cajanus cajan (L.) Millsp.]: An updating review of biology, pathogenicity and disease management. Crop Protection. 30: 951-957.

Pande, S. and Sharma, M., (2010). Climate change: potential impact on chickpea and pigeonpea diseases in the rainfed semi-arid tropics (SAT). In: $5^{\text {th }}$ International Food Legumes Research Conference (IFLRC V) \& $7^{\text {th }}$ European Conference on Grain Legumes (AEP VII), Antalya, Turkey. 26-30.

Rangaswami, G. (1958). An agar blocks technique for isolating soil microorganisms with special reference to Pythiaceous fungi. Science and Culture. 24: 85.

Reddy, M. V and Jain, K. C. (1989). Recent advances in breeding for disease resistance in pigeonpea. In: New Frontiers in Pulses Research and Development Proceedings of National Symposium. ICRISAT, Patancheru, India.

Reddy, M. V., Nene, Y.L., Raju, T.N., Sheila, V.K., Nandita Sarkar, Remanandan, P. and Amin, K.S. (1990). Disease debris field inoculation technique for phytophthora blight of pigeonpea. International Pigeonpea Newsletter. 12: 25-26.

Reddy, M.V. and Sheila, V.K. (1994). Phytophthora blight of pigeonpea: Present status and future priorities. International Journal

of Pest Management. 40(1): 98-102.

Rotem, J., Cohen, Y. and Putler, J. (1971). Relativity of limiting and optimum inoculum loads, wetting durations and temperatures for infection by Phytophthora infestans. Phytopathology. 61: 275-278.

Sarkar, N., Nene, Y.L., Reddy, M.V. and Sheila, B.K. (1992). Influence of plant age on susceptibility of pigeonpea to phytophthora blight. Indian Phytopathology. 45(4): 426-429.

Sharma, M., Pande, S., Pathak, M., Narayana Rao, Anilkumar, P., Madhusudhan, D., Benagi, V.I., et al. (2006). Prevalence of Phytophthora blight in the Deccan Plateau in India. Plant Pathology Journal. 22(4): 309-313.

Thakur, R. P., Pushpavathi, B. and Rao, V. P. (1998). Virulence characterization of single-zoospore isolates of Sclerospora graminicola from pearl millet. Plant Disease. 82(7): 747-751.

Timmer, L.W., Zitko, S.E., Gottwald, T.R. and Graham, J.H. (2000). Phytophthora brown rot of citrus: Temperature and moisture effects on infection, sporangium production and dispersal. Plant Disease. 84: 157-163.

Van der Plank, J. E. (1975). Principles of Plant Infection. Academic Press, New York. 216.

Williams, F J., Amln, K.S. and Baldev, S. (1975). Phytophthora stem blight of Cajanus cajan. Phytopathology. 65: 1029-1030.

Zhu, Y., Qian, W. and Hua, J. (2010). Temperature modulates plant defense responses through NB-LRR proteins. PLoS Pathogens. 6(4):1-12. 